\title{
Change Monitoring at Expressway Infrastructure Construction Sites Using Drone
}

\author{
Suk Bae Lee, ${ }^{1 *}$ Mihwa Song, ${ }^{2}$ Sukgu Kim, ${ }^{3}$ and Jae-Ho Won ${ }^{4}$ \\ ${ }^{1}$ Department of Civil Engineering, Gyeongnam National University of Science and Technology, \\ 33 Dongjin-ro, Jinju, Gyeongsangnam-do 52725, Republic of Korea \\ ${ }^{2}$ ICT Convergence Research Division, Korea Expressway Corporation Research Institute, \\ 208-96, Dongbu-daero 922 beon-gil, Dongtan-myeon, Hwaseong-si, Gyeonggi-do 18489, Republic of Korea \\ ${ }^{3}$ Geospatial Information Ltd., \\ A-205 Gwangju High-Tech Center, 313, Chemdangwagi-ro, Gwangju 61008, Republic of Korea \\ ${ }^{4}$ Department of Urban Engineering, Wonkwang University, \\ 460 Iksandae-ro, Iksan, Jeonlabuk-do 54538, Republic of Korea
}

(Received June 30, 2020; accepted September 8, 2020)

Keywords: UAV, 3D topographic model, deformation monitoring, orthophoto, expressway construction site, drone

Currently, unmanned aerial vehicles (UAVs) are used not only in mapping but also in various other fields such as forest research, search and rescue, and drone delivery. This study examines the possibility of deformation monitoring using UAVs at expressway construction sites in Korea. In this study, UAV photogrammetry was performed three times, and an orthophoto, digital surface model (DSM), and 3D topographic information model (TIM) of the construction site were produced through data processing. Furthermore, the construction status of the earthwork and structure work was verified with time-series images and overlapping of the 3D TIM with 2D computer-aided design (CAD) and 3D building information model (BIM) design drawings. It is concluded that it is possible to monitor deformation and construction management using UAV photogrammetry at expressway infrastructure construction sites. In addition, drones are expected to be widely used in construction sites.

\section{Introduction}

A unmanned aerial vehicle (UAV), or drone, typically refers to a pilotless aircraft that operates through a combination of technologies, including computer vision, artificial intelligence, and object avoidance technology. Drone technology has been used by defense organizations and tech-savvy consumers for a significant amount of time. However, the benefit of this technology extends well beyond these sectors. With the rising accessibility of drones, several of the most dangerous and high-paying jobs within the commercial sector are ripe for replacement by drone technology. The use cases for safe, cost-effective solutions range from data collection to delivery. ${ }^{(1)}$

Since Eisenbeiß established the concept of UAV photogrammetry in his doctoral dissertation, ${ }^{(2)}$ many studies have been conducted on the application of UAV photogrammetry. ${ }^{(3-5)}$ *Corresponding author: e-mail: sblee@gntech.ac.kr https://doi.org/10.18494/SAM.2020.2971 
Initially, studies were conducted to prove the possibility of cost-effective ${ }^{(6-9)}$ and largescale mapping. ${ }^{(10,11)}$ Lee et al. reported that stereo plotting using UAV images is possible in UAV photogrammetry, such as traditional aerial photogrammetry, and that maps created using the stereo plotting method are more accurate than maps created using the vectorization method. ${ }^{(12)}$ Rosenell and Honkavaara conducted a study on the automatic generation of highquality dense point clouds from digital images through image matching as a cutting-edge digital photogrammetric technology. ${ }^{(13)}$ Therefore, UAVs are becoming an economical and efficient means to create a digital twin of the topography. At the construction site, mapping papers for understanding the construction status and managing the construction site have been published. ${ }^{(14-16)}$ Bechtel Corporation, one of the largest construction companies in the US, is turning to UAV technology to assist with future construction projects. Bechtel started working with drones in 2015, when it partnered with Skycatch to integrate Skycatch's UAV imaging technology across its construction operations. Looking forward, Bechtel's Project 2020 initiative aims to further incorporate technology such as augmented reality, exoskeletons, autonomous vehicles, and UAVs into its construction sites. ${ }^{(17)}$ Smart construction, which is oriented toward future construction technology in several countries, is based on 3D surveying, 3D design, 3D ICT construction, and 3D inspection. Drones are becoming the most efficient means of creating digital twins based on 3D point cloud data for construction sites; therefore, the role of drones in managing construction sites to promote smart construction will continue to grow.

The Ministry of Land, Infrastructure and Transport (MOLIT) of Korea selected drones as one of the eight innovative growth engines in 2018, and has been implementing a policy to foster them. Accordingly, in the Korean National Geographic Information Institute (NGII), "Guidelines for the Public Survey Using UAV" was established in 2018, ${ }^{(18)}$ which specify standard procedures and inspection standards for applying UAV photogrammetry to public surveys at construction sites.

This study aims to analyze the possibility of change monitoring for construction management using UAVs at expressway infrastructure construction sites. For this study, UAV photogrammetry was conducted three times in accordance with the Korean NGII's "Guidelines for Public Surveys Using UAVs" at an expressway construction site in Korea. The orthophoto, digital elevation model (DEM), and 3D topographic information model (TIM) of the construction field were produced using Pix4D Mapper and Virtual Surveyor commercial software. 3D TIM created using digital surface model (DSM) and an orthophoto for the topography in the current status of construction site. Using these achievements of UAV photogrammetry by drones, time-series change detection at expressway construction sites was analyzed, and those applicable to construction management were studied.

\section{Materials and Methods}

This study aims to monitor changes at an expressway construction site using drones. For the study, a test bed was selected and UAV photogrammetry was conducted. The Pyeongtaek-Seopyeongtaek expressway construction site was selected as the test bed at the 
request of Korea Expressway Corporation, the corporation ordering this research project. Korea Expressway Corporation is a public corporation that was established in 1969, and primarily performs new expressway construction and expansion, expressway maintenance, research, and technical development of related tasks. The Pyeongtaek-Seopyeongtaek expressway construction project aims to expand the existing expressways, which have six lanes, to eight lanes by adding one lane on each side. As shown in Table 1, UAV photogrammetry was performed three times, in July, August, and September 2019, when the construction project was complete, and the deformations or changes in the drone orthophoto were analyzed during the process. As shown in Fig. 1, the test bed where UAV photogrammetry was performed was located from Seopyeongtaek IC to the Heegok Overpass, and the UAV photogrammetry was performed according to the flowchart in Fig. 2.

UAV photogrammetry was performed three times using a fixed-wing eBee Plus drone (Sensefly, Swiss) and a SODA10.6 RGB sensor with $170 \mathrm{~m}$ above elevation data (AED), and 731, 698, and 747 images were acquired. The drone weighs $1.1 \mathrm{~kg}$ and is $110 \mathrm{~cm}$ long, with a maximum flight time of $59 \mathrm{~min}$ and a flight speed of 10 to $16 \mathrm{~m} / \mathrm{s}$. An automatic path flight is possible, and the camera resolution is 20.1 MP. The drone supports the real-time kinematic (RTK) method, postprocessing method (PPK), and virtual reference station (VRS) method, and is equipped with an anemometer sensor and a ground sensor to automatically return when a high wind speed (over $12 \mathrm{~m} / \mathrm{s}$ ) occurs during the flight. When obstacles are detected, it is possible to avoid them through automatic elevation.

UAV photogrammetry was performed according to the "Guidelines for the Public Survey Using UAV". As shown in Fig. 2, the process proceeds from planning to ground control point (GCP) surveying, drone works, initial processing, aerial triangulation, building the point cloud and

Table 1

Overview of UAV photogrammetry adopted in this study.

\begin{tabular}{lccccc}
\hline Drone works day & GSD $(\mathrm{cm})$ & Overlap ratio & $\begin{array}{c}\text { Area coverage } \\
\left(\mathrm{km}^{2}\right)\end{array}$ & $\begin{array}{c}\text { Flight time } \\
(\mathrm{min})\end{array}$ & $\begin{array}{c}\text { Number of } \\
\text { images }\end{array}$ \\
\hline 17 July 2019 & 4.11 & Long $80 \%$ Side $70 \%$ & 2.53 & 57 & 731 \\
22 Aug. 2019 & 4.18 & Long $80 \%$ Side $70 \%$ & 2.64 & 65 & 698 \\
29 Sept. 2019 & 4.16 & Long 70\% Side 70\% & 2.62 & 60 & 747 \\
\hline
\end{tabular}

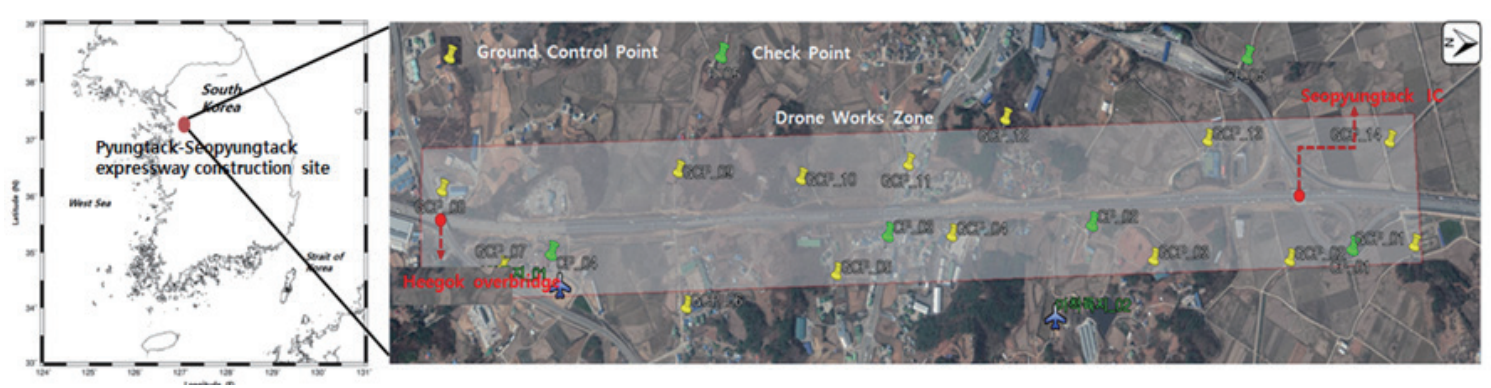

Fig. 1. (Color online) Location map of the test bed for UAV photogrammetry. 


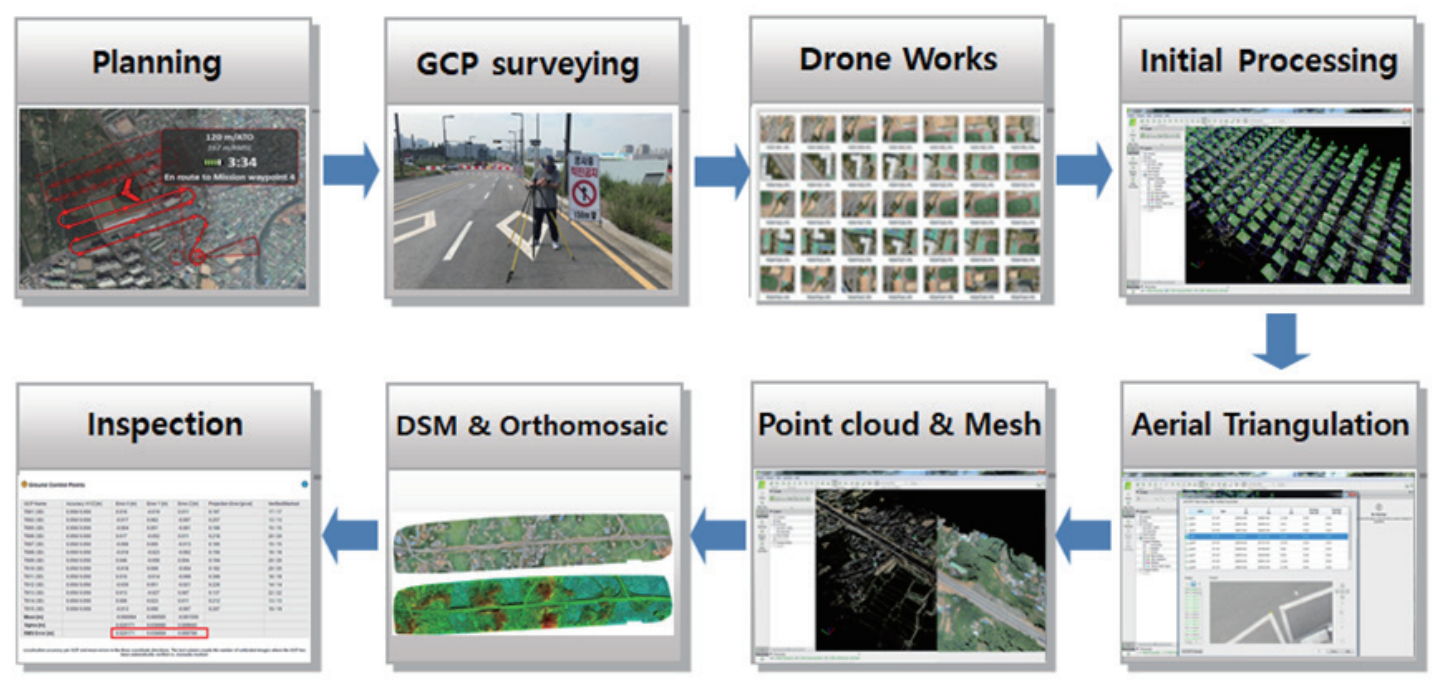

Fig. 2. (Color online) Flowchart of UAV photogrammetry performed in this study.

mesh, and producing a DSM, DEM, and orthophoto mosaic. GCP surveying was performed at 13 GCPs and six checkpoints using the global navigation satellite system (GNSS) network-RTK method for the plane and by the leveling method for the height. DEM is a model that displays the elevation of the terrain by removing natural and artificial objects such as trees, vehicles, and buildings from a DSM. The geographic coordinates of the 13 GCPs were first used to calculate exterior orientation parameters, and the exterior orientation parameters were used for bundle block adjustment in the aerial triangulation step. The accuracy of the aerial triangulation (AT) step was evaluated on the basis of the difference between the coordinates of GCPs obtained by GCP surveying and those obtained from the orthophoto mosaic. The geographic coordinates of the six checkpoints were used to check the accuracy of the orthophoto mosaic and DEM.

\section{Results}

The data obtained by the drone were processed using Pix4DMapper commercial software. Figures 3 and 4 present the DSM and orthophoto mosaic, which are the results of the UAV photogrammetry, respectively, performed three times at the Pyeongtaek-Seopyeongtaek expressway construction site. ${ }^{(19)}$

UAV photogrammetry was performed according to the "Guidelines for the Public Survey Using UAV". Table 2 presents the accuracy in the AT step given by the statistics of the difference in GCP coordinates. Table 3 presents the accuracy of the orthophoto mosaic and DEM given by the statistics of the coordinate differences at the six checkpoints.

According to Article 17 of the Guideline for Public Surveys Using UAVs, the accuracies of the horizontal position and the calculated height are required to comply with the Aerial Photogrammetry Regulation ${ }^{(20)}$ standard. Thus, in Article 56 of the Aerial Photogrammetry Regulation, the limit of the adjustment calculations and errors is defined as a root mean square 


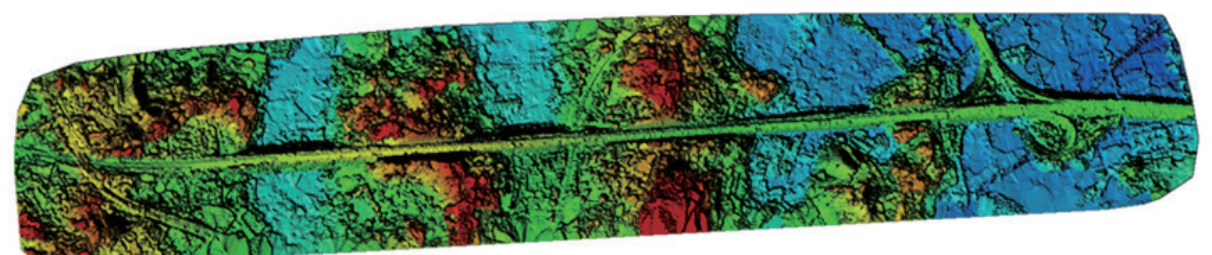

(a)

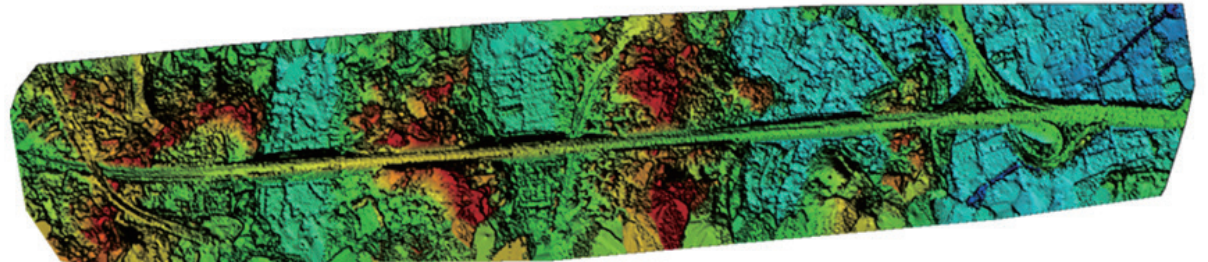

(b)

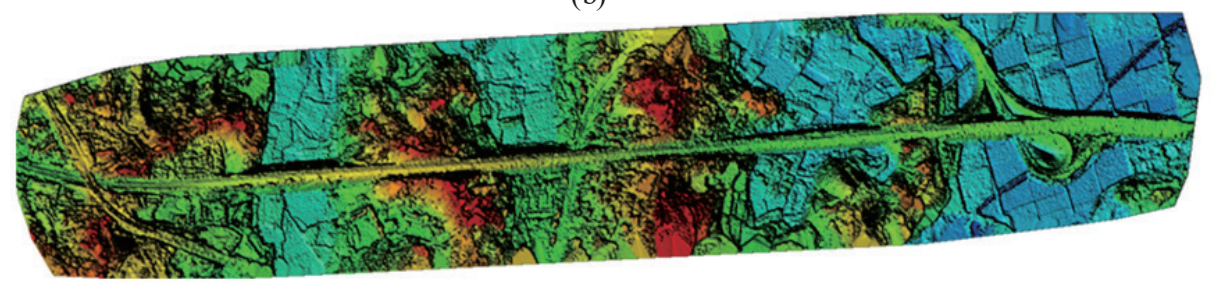

(c)

Fig. 3. (Color online) DSM at Pyeongtaek-Seopyeongtaek expressway construction site obtained by UAV photogrammetry in (a) July 2019, (b) August 2019, and (c) September 2019.

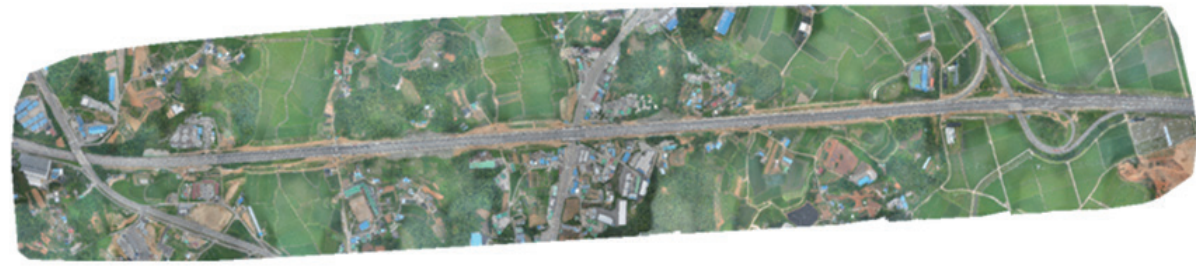

(a)

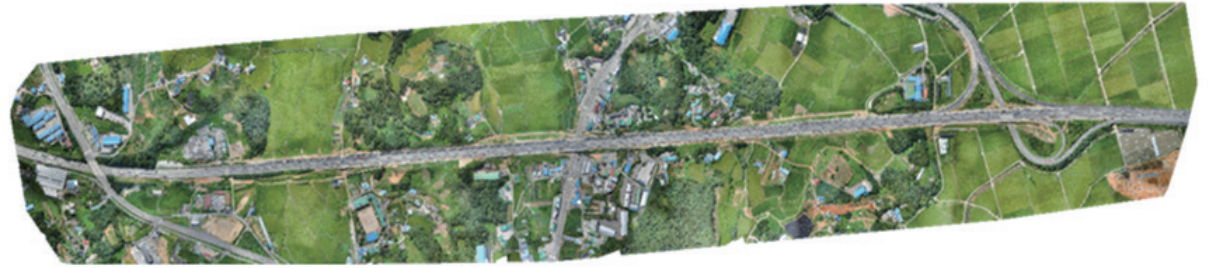

(b)

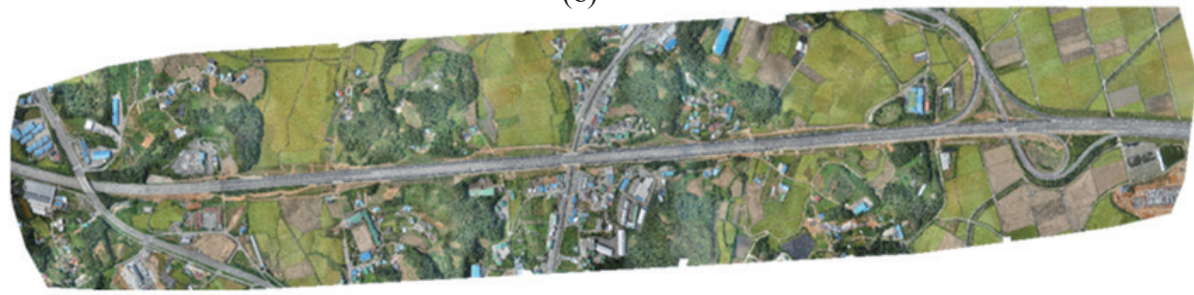

(c)

Fig. 4. (Color online) Orthophoto mosaic at Pyeongtaek-Seopyeongtaek expressway construction site obtained by UAV photogrammetry in (a) July 2019, (b) August 2019, and (c) September 2019. 
Table 2

Horizontal $(\Delta X Y)$ and vertical $(\Delta H)$ accuracies in the AT step calculated from the difference between GCP surveying coordinates and orthophoto mosaic coordinates (unit: $\mathrm{m}$ ).

\begin{tabular}{lrrrrrr}
\hline \multirow{2}{*}{ Division } & \multicolumn{2}{c}{$\begin{array}{c}\text { July UAV } \\
\text { photogrammetry }\end{array}$} & \multicolumn{2}{c}{$\begin{array}{c}\text { August UAV } \\
\text { photogrammetry }\end{array}$} & \multicolumn{2}{c}{$\begin{array}{c}\text { September UAV } \\
\text { photogrammetry }\end{array}$} \\
\cline { 2 - 7 } & \multicolumn{1}{c}{$\Delta X Y$} & $\Delta H$ & $\Delta X Y$ & $\Delta H$ & $\Delta X Y$ & $\Delta H$ \\
\hline Minimum & 0.007 & 0.029 & 0.003 & 0.005 & 0.014 & 0.003 \\
Maximum & 0.046 & 0.094 & 0.027 & 0.027 & 0.057 & 0.026 \\
Mean & 0.019 & 0.018 & 0.013 & 0.011 & 0.036 & 0.013 \\
RMSE & \pm 0.023 & \pm 0.021 & \pm 0.016 & \pm 0.016 & \pm 0.049 & \pm 0.014 \\
\hline
\end{tabular}

Table 3

Accuracies of the orthophoto mosaic $(\triangle X Y)$ and DEM $(\Delta H)$ calculated from the coordinate difference at the six checkpoints (unit: m).

\begin{tabular}{lrrrrrr}
\hline \multirow{2}{*}{ Division } & \multicolumn{2}{c}{$\begin{array}{c}\text { July UAV } \\
\text { photogrammetry }\end{array}$} & \multicolumn{2}{c}{$\begin{array}{c}\text { August UAV } \\
\text { photogrammetry }\end{array}$} & \multicolumn{2}{c}{$\begin{array}{c}\text { September UAV } \\
\text { photogrammetry }\end{array}$} \\
\cline { 2 - 7 } & \multicolumn{1}{c}{$\Delta X Y$} & $\Delta H$ & $\Delta X Y$ & $\Delta H$ & $\Delta X Y$ & \multicolumn{1}{c}{$\Delta H$} \\
\hline Minimum & 0.028 & 0.029 & 0.019 & 0.019 & 0.025 & 0.026 \\
Maximum & 0.060 & 0.094 & 0.070 & 0.067 & 0.084 & 0.074 \\
Mean & 0.042 & 0.060 & 0.039 & 0.039 & 0.058 & 0.048 \\
RMSE & \pm 0.043 & \pm 0.064 & \pm 0.042 & \pm 0.043 & \pm 0.061 & \pm 0.051 \\
\hline
\end{tabular}

error (RMSE) of $0.14 \mathrm{~m}$ and a maximum value of $0.28 \mathrm{~m}$ when the scale is 1:500 to 1:600. Thus, the results shown in Table 2 satisfy these standards. This indicates that the AT process using the Pix4DMapper software was performed significantly well. As shown in Table 3, the means of the planar and height differences were distributed from 0.039 to $0.058 \mathrm{~m}$ and from 0.039 to $0.060 \mathrm{~m}$, respectively. Moreover, the maximum differences between the planar and height differences were distributed from 0.060 to $0.084 \mathrm{~m}$ and from 0.067 to $0.094 \mathrm{~m}$, respectively. The RMSEs of the planar and height differences were distributed from \pm 0.042 to $\pm 0.061 \mathrm{~m}$ and from \pm 0.043 to $\pm 0.064 \mathrm{~m}$, respectively. Thus, the results shown in Table 3 satisfy the Korean accuracy standards of the orthophoto. Therefore, the three instances of UAV photogrammetry conducted in this study apparently performed significantly well. The orthophoto mosaic, DEM, and 3D TIM, which are the outputs of the UAV photogrammetry, can be determined to be accurate.

\section{Discussion}

In this study, we attempted to monitor change detection at the expressway construction site using the DSM, DEM, orthophoto mosaic, and 3D TIM as follows.

First, it was possible to monitor the progress of the work at the expressway construction site using the orthophoto mosaic obtained from UAV photogrammetry performed three times at intervals of one month. Figure 5 shows the change monitoring of the (a) earthwork and asphalt pavement, (b) drainage work at the road, (c) drainage work at the mountain, and (d) slope work at the Pyeongtaek-Seopyeongtaek expressway construction site. In Fig. 5(a), the orthophoto 


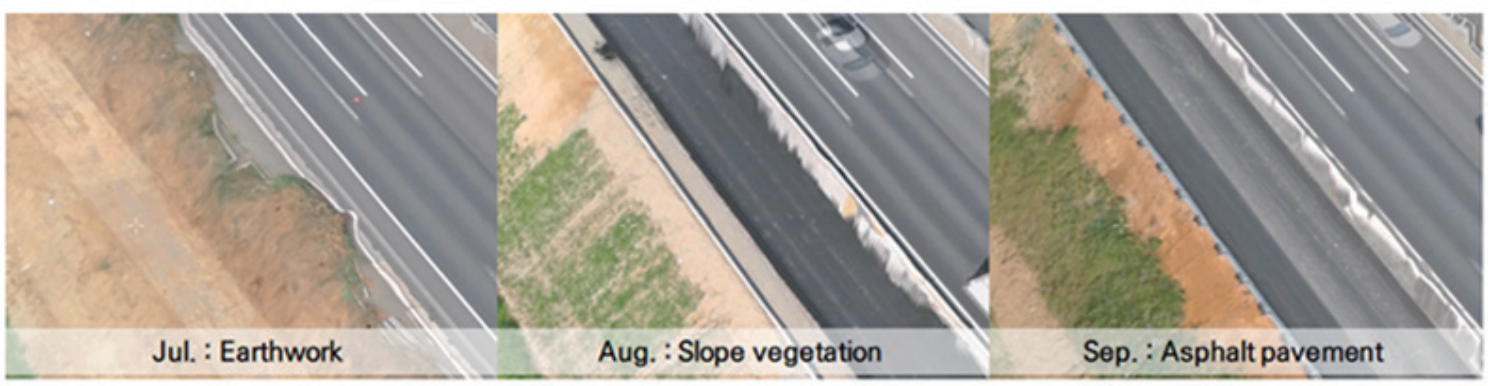

(a)

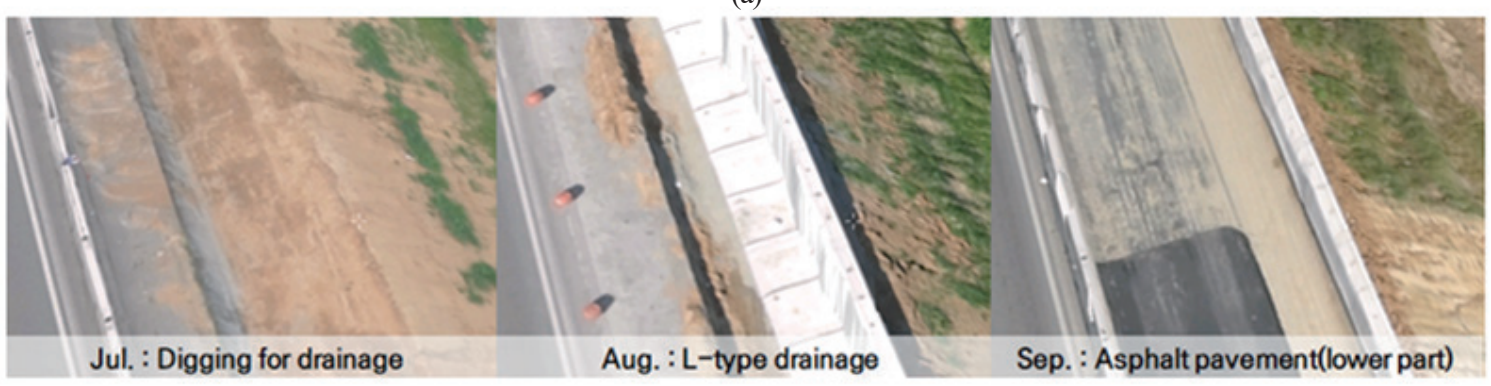

(b)

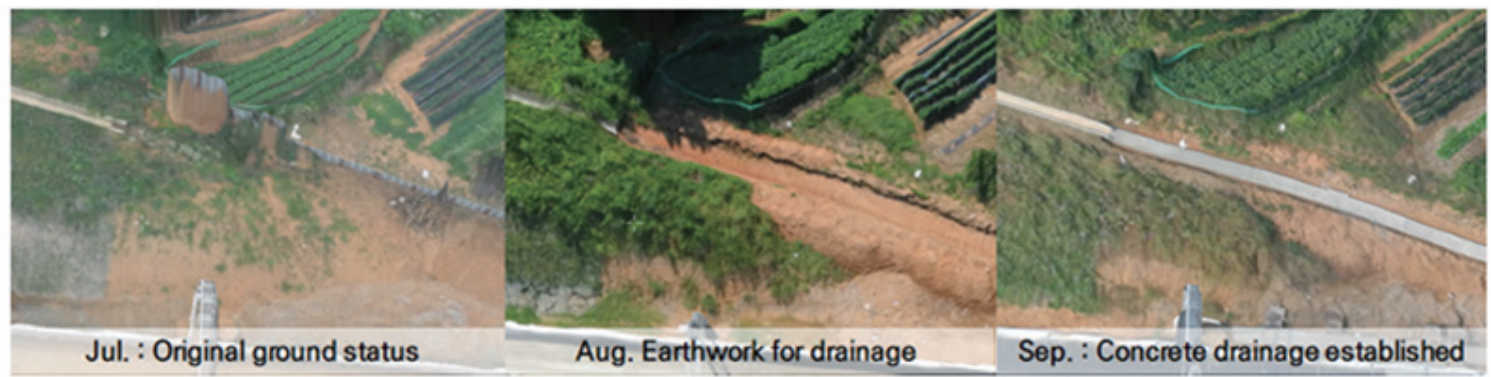

(c)

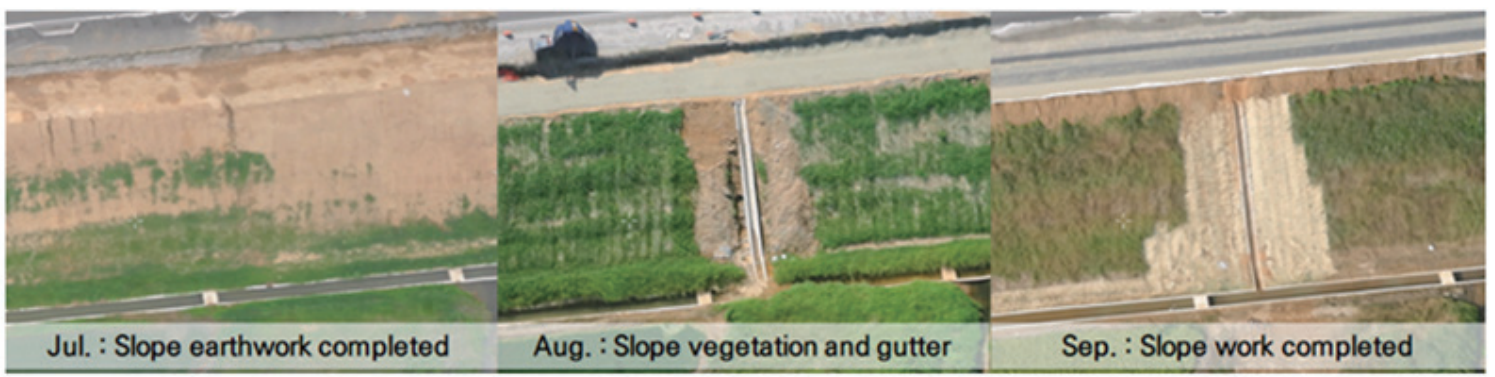

(d)

Fig. 5. (Color online) Change monitoring of (a) earthwork and asphalt pavement, (b) drainage work at the road, (c) drainage work at the mountain, and (d) slope work at Pyeongtaek-Seopyeongtaek expressway construction site.

taken in July shows the state of the earthwork on the slope of the expressway, the orthophoto taken in August shows the state of the vegetation of the slope, and the orthophoto taken in September shows that the asphalt pavement is finished. In Fig. 5(b), the three orthophotos taken in July, August, and September show the digging state of the drainage, the construction state of the L-type drainage, and the pavement of the lower asphalt, respectively. Figure 5(c) shows that the original ground status, the earthwork for drainage, and the concrete drainage 
were established from the three orthophotos taken in July, August, and September, respectively. Figure 5(d) shows the vegetation of the expressway slope and the construction of the gutter work. The orthophoto taken in July shows the completion of the earthwork on the expressway slope, and the orthophoto taken in August shows the completed state of the concrete gutter in the center of the slope. The orthophoto taken in September shows that the slope work has been completed by arranging the area around the gutter. As a result, it was found that in types of construction such as earthworks, drainage, pavement, and slope vegetation work, using a time series of orthophotos at intervals of a month, it was possible to monitor the progress of the construction.

Second, by overlapping the 3D TIM of the construction site created in this study with 2D computer-aided design (CAD) design drawings and 3D building information model (BIM) design drawings, it was possible to check the exact position and height of the structure and the construction condition of the expressway. In Fig. 6, the 3D TIM of the construction site is overlapped with 2D CAD design drawings for construction management at the (a) underpass, (b) slope ditch, and (c) boundary of the access road at the Pyeongtaek-Seopyeongtaek expressway construction site. Through these three photos, the location of the underpass and the boundary of the access road could be confirmed, and it was found that the location of the slope ditch was moved about $10 \mathrm{~m}$ to the right from the originally designed location, and the cause was identified as a design change. In Fig. 7, the 3D TIM of the construction site is overlapped with the 3D BIM design drawings for construction management at the (a) expressway road, (b) slope and berm, and (c) earthwork section at the Pyeongtaek-Seopyeongtaek expressway construction

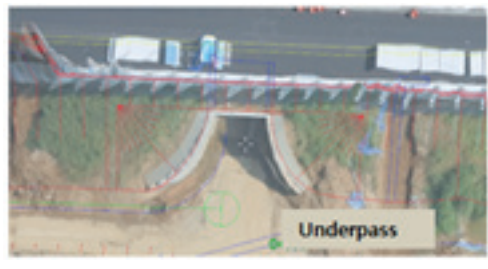

(a)

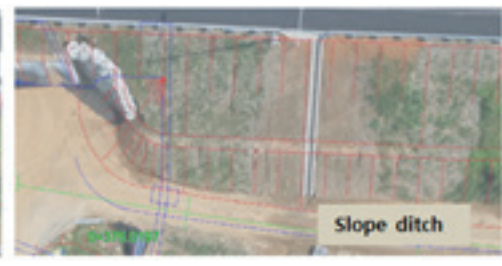

(b)

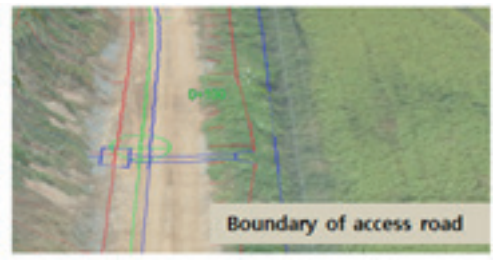

(c)

Fig. 6. (Color online) 3D TIM of the construction site overlapped with 2D CAD design drawings for construction management at (a) underpass, (b) slope ditch, and (c) boundary of access road at Pyeongtaek-Seopyeongtaek expressway construction site.

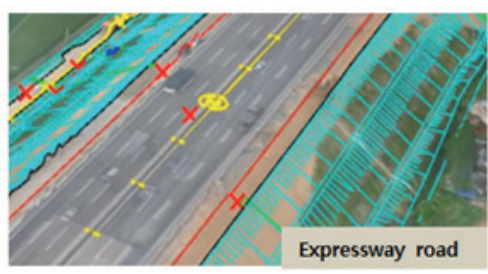

(a)

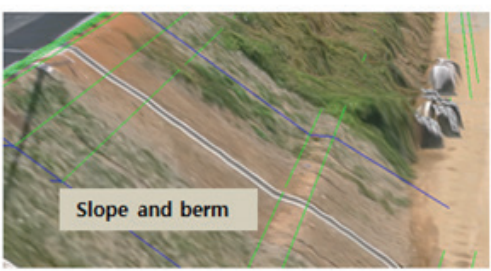

(b)

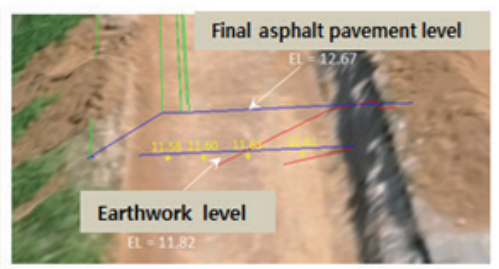

(c)

Fig. 7. (Color online) 3D TIM of the construction site overlapped with 3D BIM design drawings for construction management at (a) expressway road, (b) slope and berm, and (c) earthwork section at Pyeongtaek-Seopyeongtaek expressway construction site. 
site. Figure 7(a) shows that the 3D TIM created in this study, which is the construction completion stage, and 3D BIM design drawings are well matched. Figure 7(b) shows the result of overlapping the completed slope and berm with 3D BIM design drawings, and shows that the design and construction are properly matched. Figure 7(c) shows the result of overlapping the earthwork and pavement conditions with 3D BIM design drawings, showing that the earthwork was not completed to the earthwork level and the pavement work did not proceed to the asphalt pavement level.

Therefore, change monitoring is apparently possible at expressway construction sites if the orthophoto mosaic, DEM, and 3D TIM are used. However, unfortunately, the expressway site selected for this study had limitations because it is not a new expressway construction site but a construction site under expansion. Therefore, future studies should aim to confirm that the volume of earthworks can also be calculated through monthly time series orthophoto images and 3D TIMs at new expressway construction sites.

\section{Conclusions}

The goal of this study was to analyze the possibility of change monitoring for construction management using UAVs at expressway infrastructure construction sites. UAV photogrammetry was conducted three times at the Pyeongtaek-Seopyeongtaek expressway construction site in Korea, and an orthophoto mosaic, DEM, and 3D TIM of the construction site were produced. Through these achievements, it was possible to observe how the construction status shown in the orthophoto, such as the earthwork, drainage, structure work, and pavement work, progressed each month, and the accuracy of the location and height could be verified by overlapping with both 2D CAD design drawings and 3D BIM design drawings. Therefore, change monitoring appears to be possible using drones. In this study, it was concluded that the use of drones is sufficient for change monitoring at expressway construction sites. In addition, drones are expected to be widely used in construction sites for construction management. Therefore, in order to systematically utilize drones in many expressway construction sites, the creation of a drone works standard manual for applying drones in expressway construction sites is expected as a future task.

\section{Acknowledgments}

This work was supported by the Korea Expressway Corporation Research Institute as a 2019-2020 research project with the name "A Study on the Plan Establishment of Standard Work and Pilot Operation for Use of Drones in Construction Field".

\section{References}

138 Ways Drones Will Impact Society: From Fighting War To Forecasting Weather, UAVs Change Everything: https://www.cbinsights.com/research/drone-impact-society-uav/ (accessed July 2020).

2 H. Eisenbeiß: UAV Photogrammetry, DISS ETH NO. 18515, Ph.D. Dissertation, University of Technology Dresden, Germany (2009). 
3 K. Pothuganti, M. Jariso, and P. Kale: IJIRCCE. 5 (2017) 1170. https://doi.org/10.15680/IJIRCCE.2017. 0501126

4 A. Ahmad: Pertanika J. Sci. Technol. 19(S) (2011) 51

5 K. N. Tahar and A. Ahmad: Proc. 2011 Int. Conf. Computer Applications and Industrial Electronics (ICCAIE 2011) 443.

6 F. Neitzel and J. Klonowski: Proc. 2011 Conf. Unmanned Aerial Vehicle in Geomatics Vol.XXXVIII-1/C22. (UAV-g, 2011) 1.

7 I. Colomina and P. Molina: ISPRS J. Photogramm. Remote Sens. 92 (2014) 79. https://doi.org/10.1016/ j.isprsjprs.2014.02.013

8 M. Koeva, M. Muneza, C. Gevaert, M. Gerke, and F. Nex: Surv. Rev. 50 (2018) 361. https://doi.org/10.1080/003 96265.2016.1268756

9 S. B. Lee, Y. J. Ahn, and J. K. Noh: Proc. 21st Int. Symp. Geospatial Information Science and Urban Planning (GISUP, 2019) 143.

10 M. J. Ahmad, A. Ahmad, and K. D. Kanniah: 2018 IOP Conf. Ser.: Earth Environ. Sci. 169 (2018) 012077.

11 X. Tianyun, T. Xiaocheng, Y. Defang, X. Yonghe, and Y. Hongliang: Int. J. Control Autom. 8 (2015) 279. https://doi.org/10.14257/ijca.2015.8.3.28

12 S. B. Lee, T. Kim, Y. J. Ahn, and J. O. Lee: Sens. Mater. 31 (2019) 3797. https://doi.org/10.18494/ SAM.2019.2553

13 T. Rosenell and E. Honkavaara: Sensors 12 (2012) 453. https://doi.org/10.3990/s120100453

14 S. Bang, H. Kim, and H. Kim: Proc. 2017 ISARC, 34th Int. Symp. Automation and Robotics in Construction (ISARC, 2017) 1.

15 S. Siebert and J. Teizer: Autom. Constr. 41 (2014) 1. https://doi.org/10.1016/j.autcon.2014.01.004

16 E. Ricardo, Z. Shi, and G. Masoud: Proc. 2018 ISARC 35th Int. Symp. Automation and Robotics in Construction (ISARC, 2018). https://doi.org/10.22260/ISARC2018/0061

17 Cbinsights: From Retailers To Insurance Providers, Here Are 20 Corps Using Drone Tech Today 21 (2019) http://www.cbinsight.com (accessed March 2020).

18 National Geographical Information Institute: Guidelines for Public Surveys Using UAVs. NGII Notice No. 2018-1075 (2018) https://www.ngii.go.kr/kor/board/view.do?sq=54859\&board (accessed July 2020).

19 KECRI: A Study on the Plan Establishment of Standard Work and Pilot Operation for Use of Drones in Construction Field, Korea Expressway Corporation Research Institute, Report (2019).

20 National Geographical Information Institute: Aerial Photogrammetry Regulations. NGII Notice No. 20162609 (2016) https://www.ngii.go.kr/kor/board/view.do?sq=68737\&board (accessed July 2020).

\section{About the Authors}

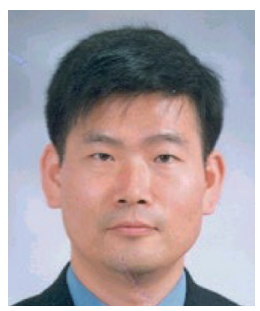

Suk Bae Lee received his B.E., M.S., and Ph.D. degrees from Sungkyunkwan University, Korea, in 1986, 1989, and 1997, respectively. From 1997 to 2003, he worked as a professor at Vision College of Jeonju. Since 2004, he has been a professor at Gyeongnam National University of Science and Technology, Korea. He was president of the Korean Society for Geospatial Information Science in 2018. His research interests are in geoid modeling, GNSS application, UAV photogrammetry, and smart construction.

(sblee@gntech.ac.kr)

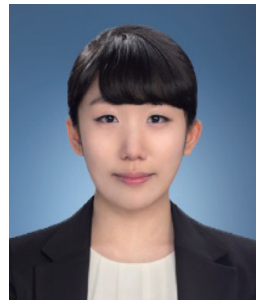

Mihwa Song received her B.S. degree from the Department of Radio Communication Engineering, Korea Maritime and Ocean University, Busan, Korea, in 2011 and her Ph.D. degree from the Department of Electrical and Computer Engineering, the University of Seoul, Seoul, Korea, in 2015. She is currently working as a deputy principal researcher at Korea Expressway Corporation Research Institute, Hwaseong, South Korea. Her current research interests include wireless communications, cooperative communications, digital multimedia broadcast, cell broadcast services, and wireless emergency alert systems. (mihwa@ex.co.kr) 


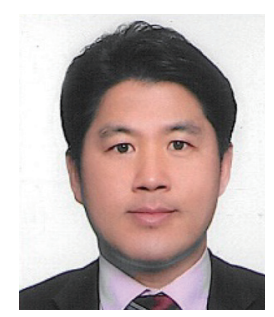

Sukgu Kim received his B.S., M.S., and Ph.D. degrees from Mokpo National University in Korea in 1995, 2006, and 2014, respectively. He established Geospatial Information Pty., Ltd., in 2000, and is serving as CEO. He has been working in the field of surveying and GIS for 25 years. Since 2011, the company has been carrying out various services and national R\&D using drone surveying technology. His research interests include GNSS application, UAV development, and photogrammetry. (gpskorea@hanmail.net).

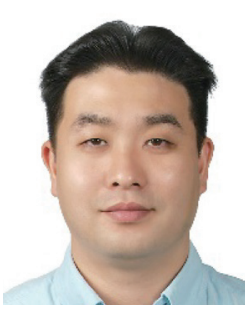

Jae-Ho Won received his B.E. degree from Korea Advanced Institute of Science and Technology (KAIST), Korea, in 1996, his M.S. degree from Seoul National University, Korea, in 1998, and his Ph.D. degree from ChungNam National University, Korea, in 2013. Since 2018, he has been a research professor at Wonkwang University, Korea. His research interests are in UAV photogrammetry, camera calibration, and remote sensing. (aerowon@nate.com) 